\title{
Biofilm formation by Mycobacterium avium isolates originating from humans, swine and birds
} Tone Bjordal Johansen*1, Angelika Agdestein ${ }^{1}$, Ingrid Olsen ${ }^{1}$,
Sigrun Fredsvold Nilsen 1 , Gudmund Holstad ${ }^{2}$ and Berit Djønne ${ }^{1}$

Address: ${ }^{1}$ Department of Animal Health, National Veterinary Institute, Pb.750 Sentrum, 0106 Oslo, Norway and ${ }^{2}$ Norwegian School of Veterinary Science, PO Box 8156 Dep, 0033 Oslo, Norway

Email: Tone Bjordal Johansen* - tone.bjordal-johansen@vetinst.no; Angelika Agdestein - angelika.agdestein@vetinst.no; Ingrid Olsen - ingrid.olsen@vetinst.no; Sigrun Fredsvold Nilsen - sigrun.nilsen@vetinst.no; Gudmund Holstad - gudmund.holstad@veths.no; Berit Djønne - berit.djonne@vetinst.no

* Corresponding author

Published: 6 August 2009

BMC Microbiology 2009, 9:159 doi:10.1186/147|-2180-9-159
Received: 24 February 2009

Accepted: 6 August 2009

This article is available from: http://www.biomedcentral.com/I47I-2/80/9/159

(C) 2009 Johansen et al; licensee BioMed Central Ltd.

This is an Open Access article distributed under the terms of the Creative Commons Attribution License (http://creativecommons.org/licenses/by/2.0), which permits unrestricted use, distribution, and reproduction in any medium, provided the original work is properly cited.

\begin{abstract}
Background: Mycobacterium avium includes the subspecies avium, silvaticum, paratuberculosis and hominissuis, and $M$. avium subspecies has been isolated from various environments all over the world including from biofilms in water distribution systems. The aim of this study was to examine isolates of $M$. avium subsp. avium and M. avium subsp. hominissuis of different origin for biofilm formation and to look for correlations between biofilm formation and RFLP-types, and to standardise the method to test for biofilm formation. In order to determine the best screening method, a panel of 14 isolates of $M$. avium subsp. avium and $M$. avium subsp. hominissuis, were tested for their ability to form biofilm in microtiter plates under different conditions. Subsequently, 83 additional isolates from humans, swine and birds were tested for biofilm formation. The isolates were tested for the presence of selected genes involved in the synthesis of glycopeptidolipids (GPLs) in the cell wall of M. avium, which is believed to be important for biofilm formation. Colony morphology and hsp65 sequvar were also determined.
\end{abstract}

Results: Nine isolates from swine produced biofilm. There was a significant higher frequency of porcine isolates forming biofilm compared to human isolates. All isolates were previously characterised by IS I 3 / I - and IS I 245-RFLP typing. The ability to form biofilm did not correlate with the RFLP-type, hsp65 sequevar, colony morphology or the presence of gene sequences related to GPL synthesis.

Conclusion: The observed differences in biofilm forming abilities between porcine and human isolates raises questions regarding the importance of biofilm formation for infectious potential. The optimised method worked well for screening of multiple isolates. 


\section{Background}

Mycobacterium avium includes the subspecies avium, silvaticum, paratuberculosis and hominissuis [1-3]. The former, $M$. avium subsp. avium causes tuberculosis in captive and free living birds [4], while M. avium subsp. hominissuis is an opportunistic environmental pathogen for humans and swine, and occasionally also for other mammals [1]. The most common forms of disease in humans are pulmonary disease, lymphadenitis and disseminated infection [5-7], while swine usually develop localised lymph node lesions [8]. Various molecular tools have been used to characterise isolates of $M$. avium, including restriction fragment length polymorphism (RFLP) [9], sequencing of the hsp65 gene [10] and multilocus sequence analysis (MLSA) [11]. In a previous study, we characterised M. avium isolates from birds, swine and humans in Norway by IS1311- and IS1245-RFLP typing. Our study demonstrated that transmission between animals and/or humans of identical isolates of $M$. avium is uncommon in Norway, and that transmission of $M$. avium from the environment to humans and animals is more likely [12]. The results are in accordance with other studies [13-15].

M. avium has been found in soils and waters worldwide [5], and isolates with identical RFLP-profiles have been found in peat and human patients and in peat and swine, respectively $[16,17]$. Drinking water has also been shown to be a possible source of $M$. avium subsp. hominissuis for both humans and swine [18-21]. M. avium has been shown to survive in water for up to 26 months, and can also survive within amoeba $[22,23]$. Additionally, potable hot water systems may contain $M$. avium concentrations greater than those found in cold water systems [24]. In natural settings, bacteria on surfaces and interfaces are found as multicellular aggregates, called biofilms [25]. M. avium has been detected in naturally occurring biofilms in water distribution systems, and has been shown to persist in drinking water biofilms for weeks $[20,26]$. M. avium may survive traditional water disinfection procedures because it is naturally resistant to water treatment with ozone and chlorine, and has been shown to be even more resistant to chlorine treatment when grown in biofilm $[22,27,28]$. Biofilms in drinking water systems may, therefore, be of importance as a reservoir for M. avium, and bacteria could be transmitted to humans and animals with drinking water. Biofilm formation in $M$. avium has been evaluated in vitro, and the ability to form biofilm varies between isolates and under different growth conditions $[29,30]$. So far, biofilm studies of $M$. avium have been performed with only a few human and environmental isolates, and biofilm studies of isolates from birds and swine have, to the authors' knowledge, not been reported.

Glycopeptidolipids (GPLs), present in the outermost layer of the cell wall of M. avium and M. smegmatis, seem to be of importance for biofilm formation in both species [29,31-33]. The GPLs of $M$. avium can be divided into non-serovar-specific (nsGPL) and serovars-specific GPL (ssGPL) [34]. Whether different serovars have different abilities to make GPL, is not known. Furthermore, GPLs are associated with colony morphology, and M. avium colonies can be smooth opaque ( $\mathrm{SmO}$ ), smooth transparent (SmT) or rough $(\mathrm{Rg})[35,36]$. The Rg variants of M. avium have been shown to have alterations in their GPLs [37].

The aim of the present study was to screen a large number of $M$. avium isolates of different origin for biofilm formation, and to correlate the ability to form biofilm with RFLP-types (published previously [12]) and hsp65 sequevars of the isolates. In addition, we wanted to examine the presence of some selected genes sequences in the GPL biosynthesis gene cluster to elucidate the importance of GPLs for biofilm formation and colony morphology. To do this, the biofilm screening method needed optimisation.

\section{Methods}

Eighty-eight Norwegian isolates of $M$. avium subspecies hominissuis from human patients $(\mathrm{n}=36)$, swine $(\mathrm{n}=51)$ and one bird and nine isolates $M$. avium subspecies avium originating from wild birds were examined for their ability to form biofilm (Figure 1). The isolates have been described previously [12]. In addition, the reference strains M. avium ATCC 25291, R13 and M. avium 104 were examined. M. smegmatis $\mathrm{mc}^{2}$ was included as a positive control for biofilm formation.

\section{Method optimisation}

A panel of $14 \mathrm{M}$. avium subsp. hominissuis (seven from humans, six from swine and one from a bird), and three M. avium subsp. avium isolates originating from birds, including the reference strains ATCC 25291 and R13, and the positive control M. smegmatis $\mathrm{mc}^{2}$ were used during optimisation of the method. The isolates all had a low passage number.

Biofilm formation was determined as previously described [30], but with some modifications. Isolates were cultured in $10 \mathrm{ml}$ Middlebrook 7H9 (BD Diagnostics, Sparks, MD) containing $10 \%$ oleic acid, albumin, dextrose and catalase (BD Diagnostics), 0.1\% Tween 80 (Merck KGaA, Darmstadt, Germany) and $0.2 \%$ glycerin (Merck) (7H9 with OADC and Tween). They were incubated with agitation $(100 / \mathrm{min})$ at $37^{\circ} \mathrm{C}$ for minimum two weeks until they reached the stationary phase at which point culture aliquots were frozen at $-70^{\circ} \mathrm{C}$. Subsequently, $100 \mu \mathrm{l}$ of frozen stock culture was inoculated in $10 \mathrm{ml}$ of fresh 7H9 with OADC and Tween and incubated at $37^{\circ} \mathrm{C}$ with agitation for seven days. $\mathrm{OD}_{600}$ was measured, and the cultures were centrifuged and resuspended to an $\mathrm{OD}_{600}$ of 0.2 in the different medias described 


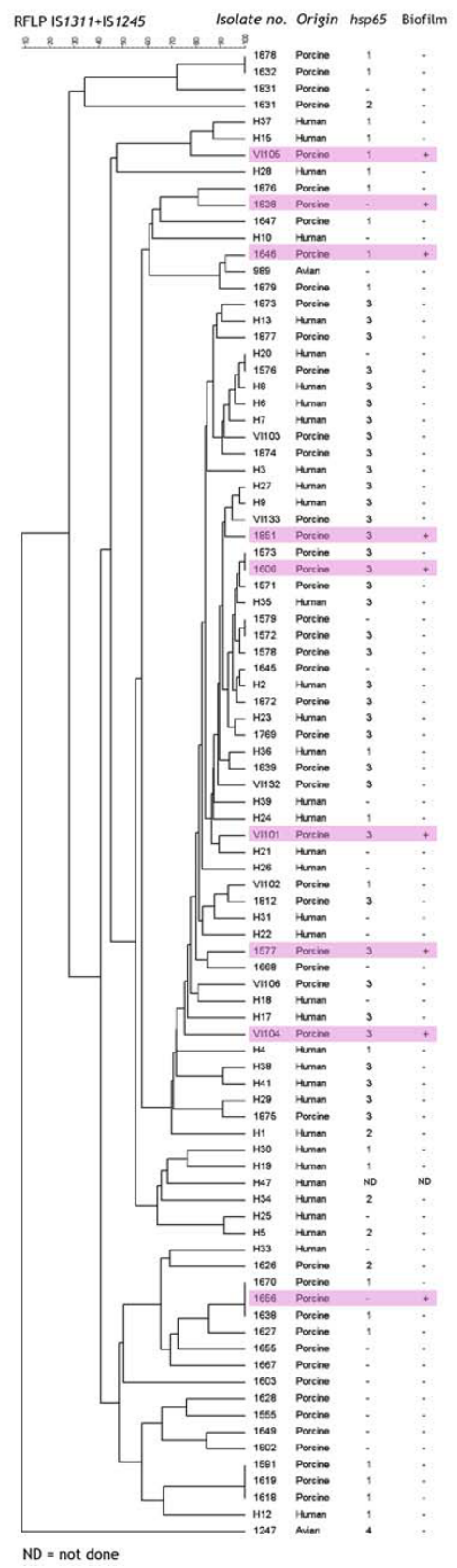

Figure I

Distribution of biofilm producing Mycobacterium avium isolates in a dendrogram based on the cluster analysis of the composite dataset of RFLP typing using both ISI III and ISI 245 as probes. A total of nine isolates of $M$. avium subspecies avium and 88 isolates of $M$. avium subsp. hominissuis isolated in Norway were included. The RFLP dendrogram has been presented elsewhere [12], but is has presently been combined with additional information regarding hsp 65 code and the biofilm forming abilities of the isolates. \#1 247 represents the identical profiles of nine avian isolates, including \#I553 and \#I794. Biofilm forming isolates have been highlighted in pink. below. $200 \mu \mathrm{l}$ of the cell suspension were added to the wells of a 96-well flat bottom polystyrene microtiter plate in triplicates (MicroWell ${ }^{\mathrm{TM}}$ Plates Nunclon ${ }^{\mathrm{TM}} \Delta$ no. 167008 (Nunc, Nuncleon, Roskilde, Denmark) [38], and incubated without agitation in a sealed container with $20 \mathrm{ml}$ sterile distilled water to prevent drying. Medium without bacteria were used as negative controls on each plate.

After incubation for two or three weeks, bacterial growth was determined by $\mathrm{OD}_{595}$ measurement. The wells were washed once with $250 \mu \mathrm{l}$ tap water, and the remaining biofilm was stained using $250 \mu \mathrm{l} 1 \%$ crystal violet (SigmaAldrich, St. Luis, MO), followed by 30 minutes incubation at room temperature. The wells were rinsed three or four times with tap water to remove unbound dye before the stained biofilm was resuspended in $250 \mu \mathrm{l}$ ethanol: acetone 70:30. Finally, the amount of biofilm was measured at $\mathrm{OD}_{595}$. Results were presented as the median value of the triplicates, subtracting the median value for the negative control.

The different media examined were: Middlebrook $7 \mathrm{H} 9$ with OADC and Tween, Middlebrook 7H9 without OADC and Tween, a mixture of 50\% sterile distilled water and 50\% Middlebrook 7H9 with OADC and Tween, sterile Hanks' Balanced Salt solution (Sigma-Aldrich), distilled water and sterile filtrated or autoclaved tap water and lake water. Different temperatures; $37^{\circ} \mathrm{C}, 28^{\circ} \mathrm{C}$ and $20^{\circ} \mathrm{C}$, and incubation time; two and three weeks, were tested using Middlebrook 7H9 with OADC and Tween.

\section{Screening of isolates}

Based on the results from the method optimisation, Middlebrook 7H9 with OADC and Tween, and incubation for two weeks at $20^{\circ} \mathrm{C}$ was selected to screen the 97 isolates, and the reference strains R13, ATCC25291 and M. avium 104 for biofilm formation. Positive control, M. smegmatis $\mathrm{mc}^{2}$ and negative control, Middlebrook 7H9 with OADC and Tween, were included on each plate. All samples were examined in triplicates. The amount of biofilm was determined as described above, with a slight modification. Before staining, $250 \mu \mathrm{l}$ methanol was used to wash the wells before the plate was left to dry for $15 \mathrm{~min}$. This methanol fixation gave less variability between repeated assays. Biofilm was stained with crystal violet as described above.

\section{Sequencing of hsp65}

The hsp65 sequencing was performed as described by Turenne et al [10]. Briefly, a 1059 bp fragment of the hsp65 gene was amplified by PCR, and the product was sequenced and analysed by BioEdit (Ibis Biosciences, Carlsbad, CA). Isolates were assigned to hsp65 codes based on the presence of single nucleotide polymor- 
phisms (SNPs) compared to the reference strain M. avium 104.

\section{Colony morphology}

The colony morphology of all isolates was examined on Middelbrook 7H10 (BD Diagnostics) medium after incubation at $37^{\circ} \mathrm{C}$ for two, three, four and five weeks. Colonies were described as smooth transparent (SmT), smoth opaque $(\mathrm{SmO})$ or rough $(\mathrm{Rg})[35]$.

\section{GPL biosynthesis genes}

Primers for the GPL biosynthesis genes $m d h t A, \operatorname{mer} A, m t f F$ (called $g s c$ by [39]), $r t f A, m t f C$ and $g t f A[39,40]$ were designed using the programme Primer 3 http:// frodo.wi.mit.edu/primer3/. Primers and Genbank accession numbers for the various genes are listed in Table 1. PCR reactions were performed with Taq DNA polymerase (Qiagen, Hilden, Germany) with the following PCR program: Initial denaturation at $94^{\circ} \mathrm{C}$ for $3 \mathrm{~min}$, followed by 30 cycles of $94^{\circ} \mathrm{C}$ for $30 \mathrm{sec}, 58^{\circ} \mathrm{C}$ for $30 \mathrm{sec}$ and $72^{\circ} \mathrm{C}$ for $30 \mathrm{sec}$. PCR products were resolved by gel electrophoresis, stained with ethidium bromide and visualised and captured under UV-light. All nine biofilm forming isolates and nine isolates closely related to these based on RFLP results [12], ten isolates harbouring ISMpa1 $[12,41]$ and 13 other isolates were screened for the presence of the six GPL biosynthesis genes. All together 42 isolates were examined (27 isolates from swine, ten from humans and five from birds including the reference strains ATCC 25291, R13 and M. avium 104).

\section{Results}

\section{Method optimisation}

Biofilm formation by the 17 isolates of $M$. avium with respect to incubation time, temperature and media is described in Figure 2. Only four isolates formed biofilm, and the greatest amount of biofilm was obtained using $7 \mathrm{H} 9$ with OADC and Tween. A mixture of $50 \%$ sterile distilled water and $50 \% 7 \mathrm{H} 9$ with OADC and Tween or $7 \mathrm{H} 9$ without OADC and Tween both gave less biofilm formation. None of the isolates showed growth or formed biofilm when incubated in Hanks' balanced salt solution or water from different sources, including distilled water, sterile filtrated or autoclaved potable water and lake water (results not shown). All temperatures and incubation times tested gave good biofilm formation by the biofilm positive isolates using 7H9 with OADC and Tween as medium. The best results were obtained at $28^{\circ} \mathrm{C}$ and by using three weeks of incubation. The trait of biofilm production was consistent between the isolates, and the nonbiofilm forming isolates were negative under all conditions (Figure 2).

\section{Screening of isolates}

Based on the results from the method optimisation, all 97 isolates plus reference strains were screened using $7 \mathrm{H} 9$ medium with OADC and Tween. For practical reasons and in order to mimic environmental conditions, incubation at $20^{\circ} \mathrm{C}$ (room temperature) for two weeks was chosen. Nine of the 97 isolates formed biofilm; all were of porcine origin and had average $\mathrm{OD}_{595}$ values ranging from 0.62 to 1.22 (Figure 3). The remaining isolates had $\mathrm{OD}_{595}$ values below 0.10 and were not regarded as biofilm forming isolates. Neither the ten bird isolates nor the 36 human isolates formed biofilm. The difference in biofilm forming abilities of isolates from swine as opposed to isolates from humans was significant by the Fisher Exact Test $(p<0.05)$. Isolates that formed biofilm belonged to nine different RFLP profiles (Figure 1), and were not genetically related based on RFLP typing.

\section{Sequencing of hsp65 and colony morphology}

Sequencing of the $h s p 65$ gene to detect single nucleotide polymorphisms (SNPs) was selected as a second method to distinguish between isolates of M. avium. The method was chosen as a complementary analysis in addition to RFLP, because it targets a genetic element that is more stable than the IS elements, with a slower "molecular clock".

Table I: Primers and GenBank coding positions for the glycopeptidolipid (GPL) genes examined in this study

\begin{tabular}{|c|c|c|c|}
\hline Gene & AFI25999 coding position & Primer sequence & Start-stop within gene (prod size in bp) \\
\hline \multirow[t]{2}{*}{ merA } & $15360-16379$ & PI02 tattgactggecctttggag & $452-659(208)$ \\
\hline & & PI03 gctttggcttcctcatatcg & \\
\hline \multirow[t]{2}{*}{$m t F$} & $16655-17377$ & PI04 gctgccgatgcttaaaagtc & $342-499(158)$ \\
\hline & & PI05 gcttctcgaaaccctgtacg & \\
\hline \multirow[t]{2}{*}{$m d h t A$} & $\mid 4389-15420$ & PI06 gacccggatgaggtctacaa & $232-402(|7|)$ \\
\hline & & PI07 gaacatctccgacgaggaag & \\
\hline \multirow[t]{2}{*}{$r t f A$} & $4488-5774$ & PI08 ccattggtcgtgaactgatg & $56-214(159)$ \\
\hline & & PI09 ttttgaagaagtcccggatg & \\
\hline \multirow[t]{2}{*}{$g t f A$} & $2807-4084$ & PII 2 ttctggaagatgggggagat & $223-400(178)$ \\
\hline & & PII 3 gcggaaggtcgtaatactcg & \\
\hline \multirow[t]{2}{*}{$m t f C$} & $5876-6676$ & PI I4 ggcgtgatctgaccaggtat & $44-266(223)$ \\
\hline & & PII5 tcttccagaaccgtttccac & \\
\hline
\end{tabular}




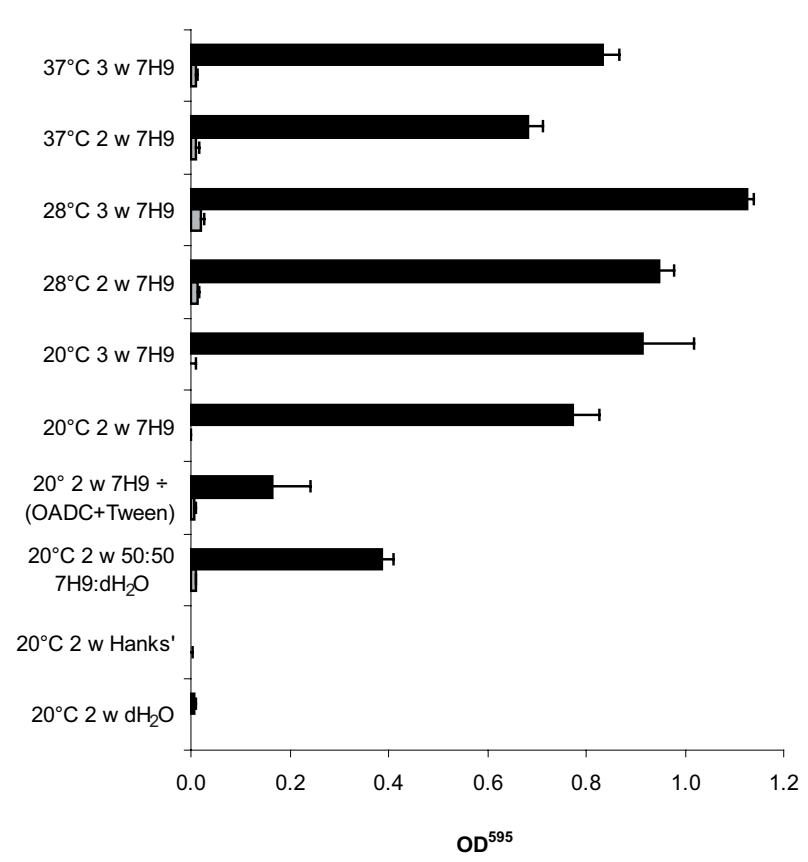

Figure 2

Biofilm formation for the different conditions tested. Fourteen Mycobacterium avium subspecies hominissuis (seven from humans, six from swine, one from a bird), and three $M$. avium subsp.avium isolates from birds were used to optimise the method. Results are represented as mean OD $^{595}$ value after crystal violet staining of biofilm + SEM (Standard error of the mean). Isolates forming biofilm (\#1646, \#1838, \#185I, \#VIIOI) are illustrated with black bars, and isolates not forming (\#HI, \#H3, \#H5, \#HI2, \#HI5, \#H28, \#H38, \#I59I, \#1831, \#989, \#I247, \#ATTC2529I, \#RI3) as grey bars. Abbreviations; $w=$ week; $7 \mathrm{H} 9=$ Middlebrook $7 \mathrm{H} 9$ with OADC and Tween; $7 \mathrm{H} 9 \div($ OADC+Tween $)=$ Middlebrook 7H9 with neither OADC nor Tween; 50:50 7H9: $\mathrm{dH}_{2} \mathrm{O}=$ $50 \%$ Middlebrook $7 \mathrm{H} 9$ with OADC and Tween and $50 \%$ distilled water; Hanks' = Hanks' balanced salt solution and $\mathrm{dH}_{2} \mathrm{O}=$ distilled water.

Seventy-two isolates were sequenced to determine the hsp 65 code, and the results are presented in Figure 1 and Table 2. All the bird isolates (M. avium subsp. avium) belonged to hsp65 code 4, and the human and porcine isolates (M. avium subsp. hominissuis) belonged to hsp65 codes 1, 2 and 3 . The biofilm forming isolates from swine were either code 1 or code 3 , but no correlation between hsp65 code and ability to form biofilm could be detected.

All isolates, except one, were either SmT or SmO after two weeks of incubation (Table 3). The reference strain ATCC 25291 was the only Rg isolate after two weeks. A few isolates had a combination of SmT and SmO colonies, and one isolate (\#1667) displayed a combination of SmO and $\mathrm{Rg}$ colonies. After three, four and five weeks of incubation the morphology changed for many of the isolates. The results are in accordance with other studies [37]. Amongst the biofilm forming isolates, both SmT and SmO colonies were observed, but none of these isolates had Rg colony morphology after two weeks.

\section{GPL biosynthesis genes}

The isolates were divided into three groups based on PCR detection of the six genes (Table 4). Group I (14 isolates) were positive for all genes examined ( $g t f A, \mathrm{rtfA}, m t f C$, $m d h t A$, merA and $m t f F$ ). Four biofilm forming isolates and all five isolates from birds (four $M$. avium subsp. avium and one $M$. avium subsp. hominissuis), including the two reference strains, belonged to this group. Group II consisted of 18 isolates negative for the ser 2 cluster genes $m d h t A$, merA and $m t f F$ and positive for the nsGPL genes $g t f A, r t f A$ and $m t f C$. Four biofilm forming isolates belonged to this group. One isolate from swine in this group harboured ISMpa1 [41]. Group III (nine isolates) were negative for all genes tested. All of these isolates harboured the ISMpa1-element $[12,41]$, and one of them (\#1656) formed biofilm. Two isolates (\#1591 and \# $1655)$ had weak positive reactions to the mtfC-PCR. Sequencing showed that they had a few basepair differences compared to AF125999/TMC724 (ATCC 25291). The PCR product of \#1591 was identical to the mtfC sequence of $M$. avium 104. In the pairs of isolates with similar or identical RFLP profiles where one formed biofilm and the other did not, five pairs had the same profile of genes, while three pairs did not. The presence or absence of these genes did not correlate with biofilm formation, as biofilm forming isolates were present in all three groups.

\section{Discussion}

In this study, a method suitable for screening a large number of $M$. avium isolates for biofilm formation was established. Ninety-seven isolates of $M$. avium subsp. avium and M. avium subsp. hominissuis originating from birds, swine and humans were examined for their biofilm forming abilities. To our knowledge, this is the first time a large number of such isolates from different hosts have been tested for biofilm formation. Nine isolates from swine formed biofilm, none of the isolates from humans or birds did. The optimised method was easy to perform, can be adapted to other test-conditions and gave clear and consistent results. A high and consistent biofilm-production was seen only when using Middlebrook 7H9, while no biofilm was detected in water. Biofilm forming abilities did not correlate with RFLP-profile, hsp65 sequevar, colony morphology or with the presence of the tested GPL biosynthesis genes.

Water has been described as the best medium for evaluation of biofilm formation $[30,42]$. Williams et al used 


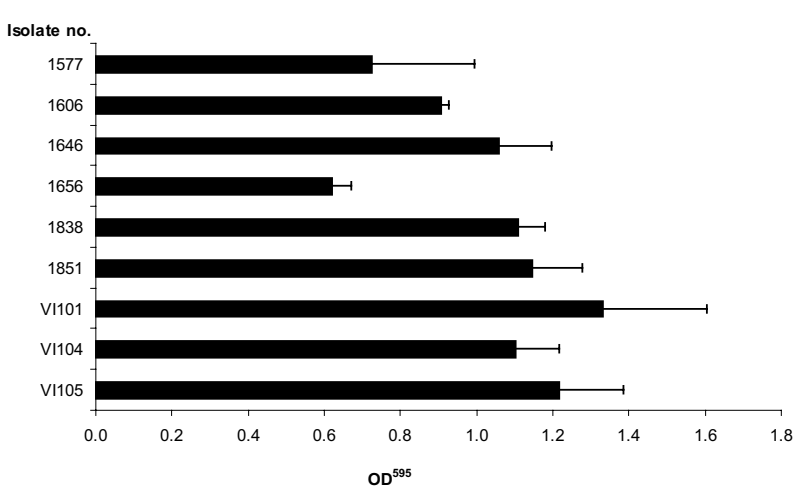

Figure 3

Differences in the amount of biofilm formed in microtiterplates amongst the nine isolates forming biofilm. Results are represented as mean $\mathrm{OD}^{595}$ value after crystal violet staining of biofilm + SEM. The calculations of mean values are based on triplicates repeated two to three times. The nine isolates were all of porcine origin.

autoclaved potable water for biofilm quantification by CFU count and imaging [42], while Geier et al. used MQ water [43]. However, our isolates did not make biofilm in water, even though different types of water and water from different sources like distilled, potable and lake water was included. This discrepancy between earlier studies and the present study can be due to different isolates tested or to other conditions in the experimental set-up. Water is not a standardised medium, and the content of ions, organic matter and the $\mathrm{pH}$ will vary depending on local factors. Carter et al. demonstrated the effect of different ions and carbon sources on biofilm formation [30]. To test a medium containing different salts and glucose, we tested our panel of isolates in Hanks's balanced salt solution, which has been described as potential biofilm media for M. avium [33,42]. However in our hands, none of the isolates formed biofilm in Hanks'.

In the present study, few isolates formed biofilm. The testing is performed under laboratory conditions, and cannot be directly transferred to bacterial behaviour in the envi- ronment. Under natural conditions bacteria are part of multispecies communities, and in nature it is possible that any M. avium isolates can be found in biofilm, regardless of whether or not it shows the ability for biofilm production under laboratory conditions. To form a biofilm, planctonic bacteria must first attach to a surface. Thereafter, they can organise into a biofilm, first as microcolonies then as macrocolonies [44]. This organising of bacterial cells is regulated by intraspecies and interspecies cell communication [45]. The autoinducer AI-2 is a universal quorum sensing signal used by many bacteria for interspecies communication [45]. M. avium has been shown to increase biofilm formation in response to AI-2, and to culture supernatant from a good biofilm producer $[30,43]$. We tested the ability to form biofilm in the laboratory under given conditions, and under such conditions, bacteria may not form biofilm due to the absence of stimuli from a microbial community.

Results from typing using IS1245- and IS1311-RFLP profiles and $h s p 65$-sequevar did not correlate with the ability to form biofilm. Even apparently genetically similar isolates, like \# 1606 and \# 1573 that had identical RFLP profiles, belonged to the same hsp65 sequevar and showed identical results by PCRs for the GPL genes, had different ability to form biofilm. Biofilm formation is probably a complex process controlled by many different gene mechanisms. The RFLP method and other fingerprinting methods are suitable for epidemiological surveys and outbreak investigations $[46,47]$, while sequencing of the hsp 65 gene can be used to phylogenetic studies [48]. In the study of complex mechanisms like biofilm and virulence, the correlation with these typing methods seemed limited.

It has been stated that GPLs are necessary for M. smegmatis to form biofilm, and that GPL-deficient mutants do not produce biofilm [31]. Similar findings are reported for $M$. avium [29,33]. In a study performed by Krzywinska and Schorey, the authors found differences between M. avium strain A5 and strain 104 regarding the GPL biosynthesis cluster. Strain 104 (serovar 1) lacks several genes belonging to the ser2 cluster (serovar 2) $[39,40,49]$, while the genes involved in synthesis of nsGPL are highly conserved

Table 2: Hsp65 code amongst the 72 tested Mycobacterium avium isolates of different origin.

\begin{tabular}{|c|c|c|c|c|c|}
\hline \multirow[b]{2}{*}{ Origin } & \multicolumn{5}{|c|}{ hsp65 code } \\
\hline & $\mathbf{I}$ & 2 & 3 & 4 & \\
\hline Avian & & & & $8(100 \%)$ & $8(100 \%)$ \\
\hline Human & $9(34 \%)$ & $3(12 \%)$ & 14 (54\%) & & $26(100 \%)$ \\
\hline Biofilm forming porcine & $2(29 \%)$ & & $5(7 \mid \%)$ & & $7(100 \%)$ \\
\hline Biofilm non-forming porcine & $12(39 \%)$ & $2(6 \%)$ & $17(55 \%)$ & & $31(100 \%)$ \\
\hline Total & $23(32 \%)$ & $5(7 \%)$ & $36(50 \%)$ & $8(11 \%)$ & 72 (100\%) \\
\hline
\end{tabular}

Ref. strains are not included in the table. 
Table 3: Colony morphology observed after two weeks incubation on Middlebrook $7 \mathrm{HI} 0$ agar at $37^{\circ} \mathrm{C}$.

\begin{tabular}{|c|c|c|c|c|}
\hline \multicolumn{5}{|c|}{ Colony morphology } \\
\hline Origin & SmT' & $\mathrm{SmO}^{2}$ & Intermediate & Total \\
\hline Avian & $8(80 \%)$ & $2(20 \%)$ & & $10(100 \%)$ \\
\hline Human & 15 (42\%) & $18(50 \%)$ & $3(8 \%)$ & $36(100 \%)$ \\
\hline Biofilm forming porcine & $7(78 \%)$ & $2(22 \%)$ & & $9(100 \%)$ \\
\hline Biofilm non-forming porcine & $19(45 \%)$ & $20(48 \%)$ & $3(7 \%)$ & $42(100 \%)$ \\
\hline Total & $49(51 \%)$ & $42(43 \%)$ & $6(6 \%)$ & 97 (100\%) \\
\hline
\end{tabular}

ISmooth transparent

${ }^{2}$ Smooth opaque

The reference strain ATCC 2529 I was the only rough $(\mathrm{Rg})$ isolate after two weeks.

Ref. strains are not included in the table.

Table 4: Presence of genes related to glycopeptidolipid synthesis, biofilm-formation, RFLP-clustering, presence of ISMpa I and hsp65code among Mycobacterium avium isolates.

\begin{tabular}{|c|c|c|c|c|c|c|}
\hline Isolates & Origin & Relation' & ISMpaI & hsp65 & nsGPL genes $^{2}$ & ser2 genes $^{3}$ \\
\hline \multicolumn{7}{|l|}{ Group I } \\
\hline 989 & Bird & & - & - & + & + \\
\hline$|553| 794$, & Bird & & - & 4 & + & + \\
\hline ATCC 2529I & Ref str. & & - & - & + & + \\
\hline $\mathrm{R} / 3$ & Ref str. & & - & 4 & + & + \\
\hline $\mathrm{H} 3 \mathrm{I}$ & Human & & - & - & + & + \\
\hline $\mathrm{H} 38$ & Human & & - & 3 & + & + \\
\hline VII05 & Swine & $\mathrm{HI5}$ & - & 1 & + & + \\
\hline $1572,1573, \mathrm{VII} 33$ & Swine & & - & 3 & + & + \\
\hline 1577 & Swine & 1668 & - & 3 & + & + \\
\hline 1606 & Swine & 1573 & - & 3 & + & + \\
\hline $185 \mid$ & Swine & VII 33 & - & 3 & + & + \\
\hline \multicolumn{7}{|l|}{ Group II } \\
\hline $\mathrm{H} 2 \mathrm{I}, \mathrm{H} 22$ & Human & & - & - & + & - \\
\hline $\mathrm{HI} 2, \mathrm{HI}, \mathrm{H} 28$ & Human & & - & 1 & + & - \\
\hline $\mathrm{HI}$ & Human & & - & 2 & + & - \\
\hline $\mathrm{HIT}$ & Human & & - & 3 & + & - \\
\hline 1555,1628 & Swine & & - & - & + & - \\
\hline 1603 & Swine & & + & - & + & - \\
\hline 1668,1831 & Swine & & - & - & + & - \\
\hline 1838 & Swine & 1876 & - & - & + & - \\
\hline 1646 & Swine & 989 & - & $\mathrm{I}$ & + & - \\
\hline 1876,1878 & Swine & & - & I & + & - \\
\hline VIIOI & Swine & $\mathrm{H} 2 \mathrm{I}$ & - & 3 & + & - \\
\hline VIIO4 & Swine & $\mathrm{HI7}$ & - & 3 & + & - \\
\hline \multicolumn{7}{|l|}{ Group III } \\
\hline 1655,1591 & Swine & & + & - & -4 & - \\
\hline 1649,1802 & Swine & & + & - & - & - \\
\hline 1656 & Swine & 1670 & + & - & - & - \\
\hline $1627,1638,1670$ & Swine & & + & I & - & - \\
\hline
\end{tabular}

The isolates are divided into three groups, I, II and III, based on presence or absence of GPL genes.

IIsolate related by RFLP (Figure I)

2nsGPL genes: gtfA, rtfA and $m t f C$

${ }^{3}$ ser2 genes: $m d h t A$, $m e r A$ and $m t f F$

${ }^{4} / 59$ I and I655 had a weak PCR product for $m t f C$. Sequencing showed a product with few bases different from AFI25999 TMC724/ATCC 2529I).

The PCR product of \#I59I was identical to the sequence of the mtfC gene of M. avium 104

Biofilm forming isolates are marked in bold typing. 
[39]. The biofilm producing abilities of these two strains has been described in other studies, and strain 104 produced less biofilm than A5 [30,33]. To investigate the significance of genes in the GPL biosynthesis ser2 cluster for the ability to form biofilm, the isolates were screened for the presence of genes involved in the synthesis and modification of nsGPL, serovar 1 and serovar $2[40,50,51]$. The isolates had three different patterns of GPL genes. Strains with a similar organisation as M. avium 104 and A5 were detected, but there was no association with biofilm formation. In addition one biofilm forming isolate lacked the genes involved in the production of nsGPL. This isolate has previously been serotyped at our institute to be serotype 10. It has been reported that serovars 5 and 10/ 11 strains do not have the single Rha residue attached by RtfA to 6-dTal, in contrast to all other serovars of M. avium $[34,52]$. The GPL produced by this serotype is not well characterised, but the presented results indicate that they may be able to produce biofilm despite the apparent lack of some genes involved in production of the most common nsGPL. As stated above, GPL has been associated with biofilm forming abilities. In the present study, presence of the GPL genes tested was not correlated with biofilm formation, but an association might be due to expression and not presence of the genes.

The significant differences in biofilm forming abilities observed between porcine and human isolates are surprising since these isolates were very similar when tested for other characteristics. Other studies have reported that isolates of human origin may form biofilm $[30,33]$, so although a significant difference in biofilm formation was observed between human and porcine isolates of $M$. avium subsp. hominissuis in the present study, this is not a consistent difference. The ability to invade bronchial epithelial cells has been demonstrated to be impaired in biofilm deficient mutants of the $M$. avium strain $\mathrm{A} 5$, and the same mutants had an impaired ability to cause infection in mice [53]. It has thus been suggested that the ability of an isolate to form biofilm is linked to virulence. Biofilm forming isolates may also reach their hosts in large numbers if loosening in clusters from a naturally occurring biofilm. The condition of the host may differ between humans and swine. Human hosts are often immunocompromised or have predisposing lung conditions $[6,54]$, while porcine hosts probably are not. Swine rarely present with clinical disease caused by M. avium subsp.hominissuis [4]. It could be speculated that swine get infected only when exposed to a large infective dose of the bacterium, for instance originating from naturally occurring biofilms, or that these biofilm related isolates are more virulent. This may lead to a selection for biofilm forming isolates in swine, explaining the differences observed in the present study.

\section{Conclusion}

An optimised method to screen isolates of Mycobacterium avium for biofilm formation was established, and this method was used to examine 97 isolates retrieved from humans, swine and birds. Nine isolates, all of porcine origin, formed biofilm. No correlation was found between the ability of the isolates to form biofilm with the presence of selected GPL genes. The biofilm forming isolates were not related by RFLP or $h s p 65$ sequencing. The differences observed between the porcine and human isolates raises questions regarding their biofilm forming abilities and the importance of biofilm production for their infectious potential.

\section{Authors' contributions}

TBJ contributed to conception and design, laboratory experiments, analysed data and drafted the manuscript. AA contributed to design, laboratory experiments, analysed data, and the writing of manuscript. SFN contributed to laboratory experiments, data analysis and writing of manuscript. IO, GH and BD contributed to conception and design, data analysis and the writing of manuscript. All authors have read and approved the final manuscript.

\section{Acknowledgements}

We would like to thank Prof. Tone Tønjum (Rikshospitalet University Hospital, Norway) and Dr. Ulf R. Dahle (Norwegian Institute of Public Health) for providing human isolates and Dr. Dick van Soolingen (National Institute of Public Health and the Environment, Bilthoven, the Netherlands) for providing the reference strain RI3. We would also thank Dr. Finn Saxegaard for collecting bird- and porcine isolates and Vivi Myrann for technical assistance. Dr. Live Nesse and Lene Vestby are gratefully acknowledged for helping to establish biofilm methodologies and for helping with data

interpretation. We are also grateful to Dr. Rolf Bjerke Larsen (Norwegian School of Veterinary Medecine) for his help with the statistical analysis.

Finally, we would like to thank Dr. Hannah Jørgensen for proofreading the manuscript. This work was partly funded by the Norwegian research Council, project no. 173498.

\section{References}

I. Mijs W, de Haas P, Rossau R, Laan T van der, Rigouts L, Portaels F, et al.: Molecular evidence to support a proposal to reserve the designation Mycobacterium avium subsp. avium for bird-type isolates and 'M. avium subsp. hominissuis' for the human/porcine type of M. avium. Int J Syst Evol Microbiol 2002, 52:I505-I5I8.

2. Thorel MF, Krichevsky M, Levy-Frebault VV: Numerical taxonomy of mycobactin-dependent mycobacteria, emended description of Mycobacterium avium, and description of Mycobacterium avium subsp. avium subsp. nov., Mycobacterium avium subsp. paratuberculosis subsp. nov., and Mycobacterium avium subsp.silvaticum subsp. nov. Int J Syst Bacteriol 1990, 40:254-260.

3. Turenne CY, Wallace R Jr, Behr MA: Mycobacterium avium in the postgenomic era. Clin Microbiol Rev 2007, 20:205-229.

4. Thorel MF, Huchzermeyer H, Weiss R, Fontaine J]: Mycobacterium avium infections in animals. Literature review. Vet Res 1997, 28:439-447.

5. Falkinham JO III: Epidemiology of infection by nontuberculous mycobacteria. Clin Microbiol Rev 1996, 9:177-2 I5.

6. Ashford DA, Whitney E, Raghunathan P, Cosivi O: Epidemiology of selected mycobacteria that infect humans and other animals. Rev Sci Tech 200I, 20:325-337. 
7. Inderlied CB, Kemper CA, Bermudez LE: The Mycobacterium avium complex. Clin Microbiol Rev 1993, 6:266-3I0.

8. Thorel MF, Huchzermeyer HF, Michel AL: Mycobacterium avium and Mycobacterium intracellulare infection in mammals. Rev Sci Tech 200I, 20:204-2I8.

9. Guerrero C, Bernasconi C, Burki D, Bodmer T, Telenti A: A novel insertion element from Mycobacterium avium, ISI245, is a specific target for analysis of strain relatedness. J Clin Microbiol 1995, 33:304-307.

10. Turenne CY, Semret M, Cousins DV, Collins DM, Behr MA Sequencing of hsp65 distinguishes among subsets of the Mycobacterium avium complex. I Clin Microbiol 2006, 44:433-440.

II. Turenne CY, Collins DM, Alexander DC, Behr MA: Mycobacterium avium subsp. paratuberculosis and $M$. avium subsp. avium are independently evolved pathogenic clones of a much broader group of $\mathbf{M}$. avium organisms. J Bacteriol 2008, I 90:2479-2487.

12. Johansen TB, Olsen I, Jensen MR, Dahle UR, Holstad G, Djønne B New probes used for IS I 245 and IS I 3 I I restriction fragment length polymorphism of Mycobacterium avium subsp. avium and Mycobacterium avium subsp.hominissuis isolates of human and animal origin in Norway. BMC Microbiol 2007, 7:14.

13. Mobius P, Lentzsch P, Moser I, Naumann L, Martin G, Kohler H Comparative macrorestriction and RFLP analysis of Mycobacterium avium subsp. avium and Mycobacterium avium subsp. hominissuis isolates from man, pig, and cattle. Vet Microbiol 2006, I I 7:284-29|.

14. O'Grady D, Flynn O, Costello E, Quigley F, Gogarty A, McGuirk J, et al.: Restriction fragment length polymorphism analysis of Mycobacterium avium isolates from animal and human sources. Int J Tuberc Lung Dis 2000, 4:278-28I.

15. Tirkkonen T, Pakarinen J, Moisander AM, Makinen J, Soini H, li-Vehmas T: High genetic relatedness among Mycobacterium avium strains isolated from pigs and humans revealed by comparative IS I 245 RFLP analysis. Vet Microbiol 2007, I 25: I75- I8I.

16. Bauer J, Andersen AB, Askgaard D, Giese SB, Larsen B: Typing of clinical Mycobacterium avium complex strains cultured during a 2-year period in Denmark by using IS I 245. J Clin Microbiol 1999, 37:600-605

17. Matlova L, Dvorska L, Ayele WY, Bartos M, Amemori T, Pavlik I: Distribution of Mycobacterium avium complex isolates in tissue samples of pigs fed peat naturally contaminated with mycobacteria as a supplement. I Clin Microbiol 2005, 43: I 26I-I 268.

18. Nishiuchi Y, Maekura R, Kitada S, Tamaru A, Taguri T, Kira Y, et al.: The recovery of Mycobacterium avium-intracellulare complex (MAC) from the residential bathrooms of patients with pulmonary MAC. Clin Infect Dis 2007, 45:347-35I.

19. Hilborn ED, Yakrus MA, Covert TC, Harris SI, Donnelly SF, Schmitt MT, et al.: Molecular comparison of Mycobacterium avium isolates from clinical and environmental sources. Appl Environ Microbiol 2008, 74:4966-4968.

20. Falkinham JO III, Norton CD, LeChevallier MW: Factors influencing numbers of Mycobacterium avium, Mycobacterium intracellulare, and other mycobacteria in drinking water distribution systems. Appl Environ Microbiol 200 I, 67:|225-I23I.

21. von Reyn CF, Maslow JN, Barber TW, Falkinham JO III, Arbeit RD: Persistent colonisation of potable water as a source of Mycobacterium avium infection in AIDS. Lancet I994, 343: I | 37- I | 4 |

22. Hilborn ED, Covert TC, Yakrus MA, Harris SI, Donnelly SF, Rice EW, et al:: Persistence of nontuberculous mycobacteria in a drinking water system after addition of filtration treatment. Appl Environ Microbiol 2006, 72:5864-5869.

23. Vaerewijck MJ, Huys G, Palomino JC, Swings J, Portaels F: Mycobacteria in drinking water distribution systems: ecology and significance for human health. FEMS Microbiol Rev 2005, 29:9 I I-934.

24. du Moulin GC, Stottmeier KD, Pelletier PA, Tsang AY, Hedley-Whyte $\mathrm{J}$ : Concentration of Mycobacterium avium by hospital hot water systems. JAMA 1988, 260:1599-1601.

25. Branda SS, Vik Å, Friedman L, Kolter R: Biofilms: the matrix revisited. Trends Microbiol 2005, I 3:20-26.

26. Torvinen E, Lehtola MJ, Martikainen PJ, Miettinen IT: Survival of Mycobacterium avium in drinking water biofilms as affected by water flow velocity, availability of phosphorus and temperature. Appl Environ Microbiol 2007, 73:6201-6207.

27. Taylor RH, Falkinham JO III, Norton CD, LeChevallier MW: Chlorine, chloramine, chlorine dioxide, and ozone susceptibility of Mycobacterium avium. Appl Environ Microbiol 2000, 66: $1702-1705$

28. Steed KA, Falkinham JO III: Effect of growth in biofilms on chlorine susceptibility of Mycobacterium avium and Mycobacterium intracellulare. Appl Environ Microbiol 2006, 72:4007-40 I I.

29. Freeman R, Geier H, Weigel KM, Do J, Ford TE, Cangelosi GA: Roles for cell wall glycopeptidolipid in surface adherence and planktonic dispersal of Mycobacterium avium. Appl Environ Microbiol 2006, 72:7554-7558.

30. Carter G, Wu M, Drummond DC, Bermudez LE: Characterization of biofilm formation by clinical isolates of Mycobacterium avium. I Med Microbiol 2003, 52:747-752.

31. Recht J, Kolter R: Glycopeptidolipid acetylation affects sliding motility and biofilm formation in Mycobacterium smegmatis. J Bacteriol 200I, I 83:57|8-5724.

32. Recht J, Martinez A, Torello S, Kolter R: Genetic analysis of sliding motility in Mycobacterium smegmatis. I Bacteriol 2000, | 82:4348-435 I.

33. Yamazaki Y, Danelishvili L, Wu M, Macnab M, Bermudez LE: Mycobacterium avium genes associated with the ability to form a biofilm. Appl Environ Microbiol 2006, 72:819-825

34. Chatterjee $\mathrm{D}$, Khoo $\mathrm{KH}$ : The surface glycopeptidolipids of mycobacteria: structures and biological properties. Cell Mol Life Sci 200I, 58:2018-2042.

35. Belisle JT, Brennan PJ: Molecular basis of colony morphology in Mycobacterium avium. Res Microbiol I 994, I 45:237-242.

36. Schorey JS, Sweet L: The mycobacterial glycopeptidolipids: structure, function, and their role in pathogenesis. Glycobiology 2008, I 8:832-84|

37. Belisle JT, Klaczkiewicz K, Brennan PJ, Jacobs WR Jr, Inamine JM: Rough morphological variants of Mycobacterium avium. Characterization of genomic deletions resulting in the loss of glycopeptidolipid expression. J Biol Chem 1993. 268: $10517-10523$.

38. Woodward MJ, Sojka M, Sprigings KA, Humphrey TJ: The role of SEFI 4 and SEFI 7 fimbriae in the adherence of Salmonella enterica serotype Enteritidis to inanimate surfaces. I Med Microbiol 2000, 49:48I-487.

39. Krzywinska E, Schorey JS: Characterization of genetic differences between Mycobacterium avium subsp. avium strains of diverse virulence with a focus on the glycopeptidolipid biosynthesis cluster. Vet Microbiol 2003, 91:249-264.

40. Eckstein TM, Belisle JT, Inamine JM: Proposed pathway for the biosynthesis of serovar-specific glycopeptidolipids in Mycobacterium avium serovar 2. Microbiology 2003, 149:2797-2807.

4I. Olsen I, Johansen TB, Billman-Jacobe H, Nilsen SF, Djønne B: A novel IS element, ISMpaI, in Mycobacterium avium subsp. paratuberculosis. Vet Microbiol 2004, 98:297-306.

42. Williams MM, Yakrus MA, Arduino MJ, Cooksey RC, Crane CB, Banerjee $\mathrm{SN}$, et al:: Structural analysis of biofilm formation by rapidly and slowly growing nontuberculous mycobacteria. App Environ Microbiol 2009, 75:2091-2098.

43. Geier H, Mostowy S, Cangelosi GA, Behr MA, Ford TE: Autoinducer-2 triggers the oxidative stress response in Mycobacterium avium, leading to biofilm formation. Appl Environ Microbio 2008, 74:1798-1804.

44. Monds RD, O'Toole GA: The developmental model of microbial biofilms: ten years of a paradigm up for review. Trends Microbiol 2009, I 7:73-87.

45. Henke JM, Bassler BL: Bacterial social engagements. Trends Cell Biol 2004, I 4:648-656.

46. Mostowy S, Behr MA: The origin and evolution of Mycobacterium tuberculosis. Clin Chest Med 2005, 26:207-2vi.

47. van Soolingen D: Molecular epidemiology of tuberculosis and other mycobacterial infections: main methodologies and achievements. J Intern Med 2001, 249:1-26.

48. Rastogi N, Legrand E, Sola C: The mycobacteria: an introduction to nomenclature and pathogenesis. Rev Sci Tech 200I, 20:2 I-54.

49. Miyamoto Y, Mukai T, Nakata N, Maeda Y, Kai M, Naka T, et al.: Identification and characterization of the genes involved in glycosylation pathways of mycobacterial glycopeptidolipid biosynthesis. J Bacteriol 2006, I 88:86-95

50. Maslow JN, Irani VR, Lee SH, Eckstein TM, Inamine JM, Belisle JT: Biosynthetic specificity of the rhamnosyltransferase gene of Mycobacterium avium serovar 2 as determined by allelic exchange mutagenesis. Microbiology 2003, I49:3193-3202. 
5I. Eckstein TM, Silbaq FS, Chatterjee D, Kelly NJ, Brennan PJ, Belisle JT: Identification and recombinant expression of a Mycobacterium avium rhamnosyltransferase gene ( $r t f A)$ involved in glycopeptidolipid biosynthesis. J Bacteriol 1998, I 80:5567-5573.

52. Aspinall GO, Chatterjee D, Brennan PJ: The variable surface glycolipids of mycobacteria: structures, synthesis of epitopes, and biological properties. Adv Carbohydr Chem Biochem 1995, 5I:169-242.

53. Yamazaki Y, Danelishvili L, Wu M, Hidaka E, Katsuyama T, Stang B, et al.: The ability to form biofilm influences Mycobacterium avium invasion and translocation of bronchial epithelial cells. Cell Microbiol 2006, 8:806-8I4

54. Jarzembowski JA, Young MB: Nontuberculous mycobacterial infections. Arch Pathol Lab Med 2008, I32:1333-134I.

Publish with Bio Med Central and every scientist can read your work free of charge

"BioMed Central will be the most significant development for disseminating the results of biomedical research in our lifetime. "

Sir Paul Nurse, Cancer Research UK

Your research papers will be:

- available free of charge to the entire biomedical community

- peer reviewed and published immediately upon acceptance

- cited in PubMed and archived on PubMed Central

- yours - you keep the copyright

Submit your manuscript here:

http://www.biomedcentral.com/info/publishing_adv.asp
BiolMedcentral 